\title{
INVESTIGATION OF FEEDING ROLLERS ALIGNMENT IN A HORIZONTAL PLANE
}

\author{
Ol'ga Tarasova* \\ Volga State University of Technology, Yoshkar-Ola, Russia \\ Mariia Chernova \\ Volga State University of Technology, Yoshkar-Ola, Russia
}

This research represents the ways of estimation of woodworking machines' feed roll-ers arrangement in a horizontal plane as exemplified by control of the position of the feed rollers axes on a frame saw. Some significant considerations have been stated in relation to standard methods of control GOST 10294, which contain accuracy value and monitoring techniques. Some methods are recommended in the following research, which allow monitor-ing value of possible deviations of mutual arrangement of feed rollers in a horizontal plane. This is done with due consideration of inaccuracy of their setting, as well as radial beats that results from exploitation, by means of conducting measurements in two mutually perpendicu-lar planes.

Key words: Arrangement accuracy, Axes alignment, Feeding rollers, Setting inaccuracy

\section{INTRODUCTION}

Produce of solid timber has been in favour in all countries, in comparison with composite and polymeric materials. It has certain advantages in ecological and esthetic rates. It features high solidity, but as all materials it possesses some drawbacks, namely: anisotropic properties, flammability, non waterproof, a bit difficult in processing etc. Industrial timber stocks decrease gradually. Legal and illegal cutting, forest fires and other factors contribute much to this process. For this reason, manufactures have to solve the problem of efficient use of round timber involving added-value wood conversion, introduction of new technologies of processing and application of immediate diagnosing of woodworking machinery status.

Analyzing the situation in fitting enterprises of woodworking complex, specifically in Mari El Republic, Russia, it should be noted that manufacture of doors, windows, parquet blocks and other types of products often use machinery fitted in the 80 -th of the previous century. Some minor exceptions are enterprises equipped in the early 2000. Physical deterioration and obsolescence of machine-tool holding arises. Only up-to-date diagnosing and scheduled preventive repair with adjustment on manufacturing and geometrical accuracy together with replacing of cutting tool provide an opportunity to accomplish production of quality products, which meet all consumers' requirements $[10,1,12]$.

Methods of diagnosing produce, tools, log-processing equipment (log frame) and other appliances are regulated in GOST $2140-81$, GOST 5524 - 75, GOST 10294 - 90 [02, 03, 04], RPI $[09,11]$ and other reference documents. In order to adhere accuracy parameters of adjustment, equipment design should provide access of diagnostic devices to control points and cross-sections without disassembly of units and mechanisms. This should eliminate possibility of damaging the objects while connected to diagnostic (control) devices.

Aim of the research: creation of the elements of immediate diagnosing system of the position of interworking parts of log-processing equipment in a horizontal plane. It should be based on the investigation and improvement of standard control methods with elaboration and standardization of new techniques.

Objectives under solution:

1) to analyze reference documents and technical publications about control methods of geometrical and technological adjustment of log frame;

2) to substantiate type and construction for evaluation of deviation rectilinear surfaces (flat and cylindrical) from horizontal position of basing and guiding devices of woodwork- 
ing machines and log frames.

3 ) to develop new techniques (instead of obsolete standards) on the basis of patented device and evaluate horizontal misalignment.

The analysis of publications and reference documents $[4,5,6,7]$ has allowed to reveal about 40 control rates of log-processing equipment. Only $30 \%$ of them have standard techniques, most of which are out of date and considered to be improper.

Relating to the process of timber manufacturing special attention should be given to the principal goals of technical diagnostics:

- evaluation of equipment technical condition;

- establishing quantitative connections between inaccuracies of timber and log-processing equipment;

- risk assessment and working out of corrective actions subsequent to the results of equipment status control;

- maintenance engineering and equipment repair;

- feasibility study of further equipment service by taking into account forecasting of its technical condition with revealed defects involving the use of numerical scheme [10].

It is necessary to note that log frame construction is practically controllable without additional disassembling if upper and lower front gates are open. Therefore evaluation of technical status of mutually arranged parts of feeding and cutting mechanisms represents no difficulty, excluding lack of improved methods of immediate control.

The analysis of GOST 10294 has made possible to highlight some drawbacks of typical checkouts. Accordingly, most significant of them, in estimating horizontality of lower feeding rollers axes and location of lower feeding rollers in one horizontal plane could be considered as:

- complication in basing the level on a narrow tested surface of a straightedge;

- under considerable vibrations and inertial loads inclination of footing and frame may exceed measurement limits of the level.

An invention is proposed in order to get through revealed troubleshooting. It refers to the field of measurements of rectilinear surfaces (flat and cylindrical) deviation from horizontal position and can be applied to increase measurement accuracy of these deviations by means of block levels of common accuracy in different branches of engineering. It is especially good for assessment of mutual parallelism of the feeding rollers axes on basing and guiding devices in wood-working machines and log frames.

This technique includes level adjustment in a horizontal position on the tested surface with the help of special inclinometer. It differs in the fact that departure from horizontality measurement is carried out by means of detection device, while the level is used only for identification of horizontal position of inclinometer base.

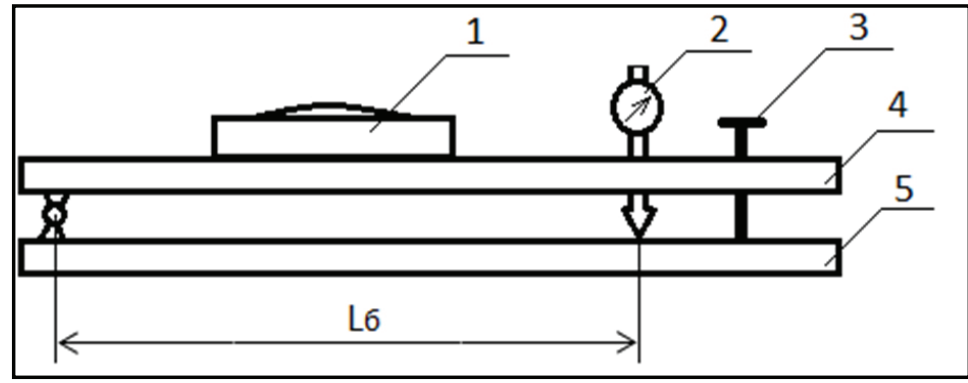

Figure 1: Inclinometer

Special inclinometer (Figure 1), placed on the tested surface, consists of two pivotally connected plain-parallel bars, one of which is a support block -5 , and another one is inclinable block -4 , it serves as a support for level -1 . For setting in horizontal axis an adjusting screw -3 is used. For measurement of inclination angle - indicator depthometer is used.
Depending from measurable value, L $\sigma$ - a baseline from the pivot axis to indicator axis is determined. The following technique [8] permits to decrease:

- random inaccuracy in measuring device basing;

- time and labour input needed for multiple metering in order to get average result with the given accuracy and reliability. 
According to the analysis and the invention, which was mentioned above, new techniques and facilities have been developed (Devices 1 and 2, represented in diagrams 1 and 3). They permit to estimate position of the rollers in a horizontal plane immediately without equipment disassembling. Besides, they give an opportunity to consider inaccuracies of the installation, including existence of radial beats of the rollers by means of conducting measurements within mutually perpendicular planes.

Table 1: Horizontality of the axes of lower feeding rollers

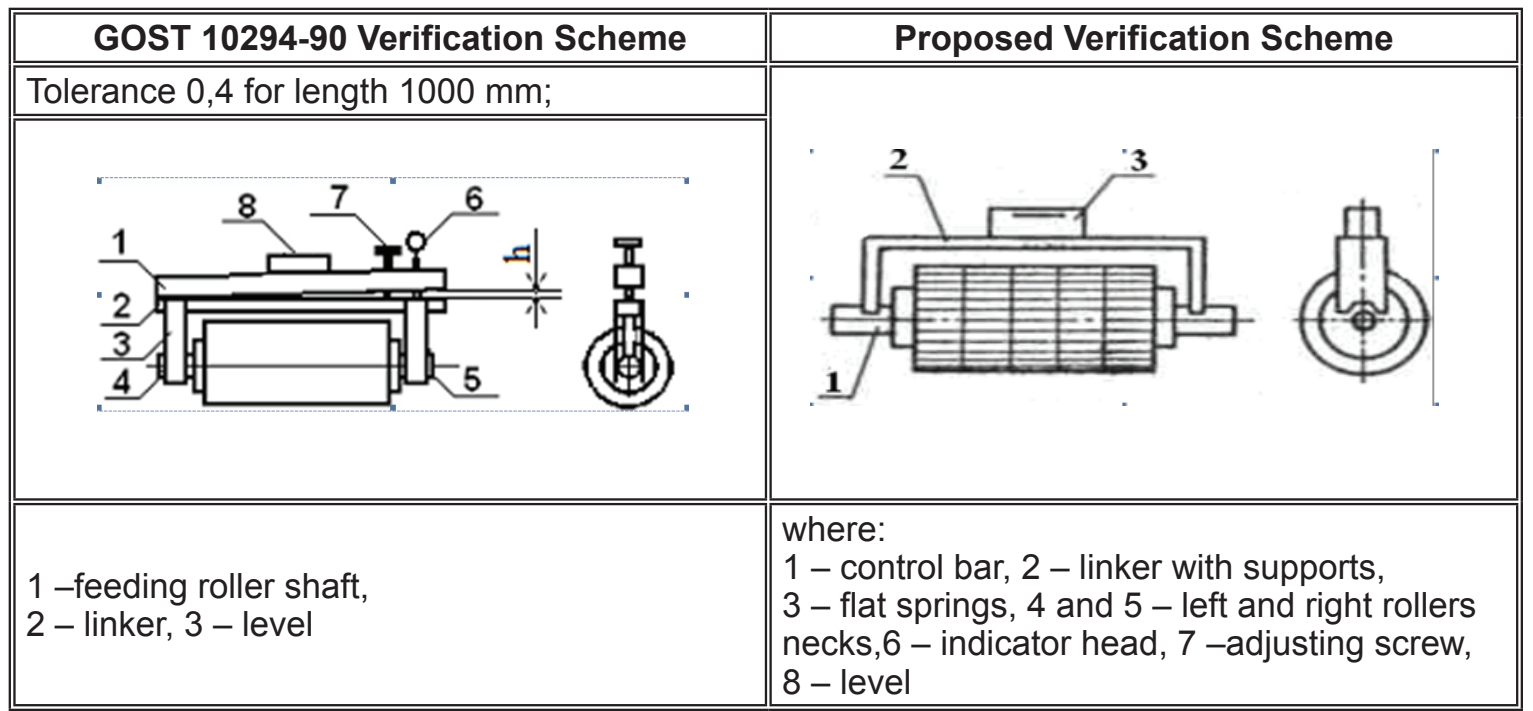

To conduct measurements it is necessary to make key lines on a shaft or a tooth wheel with graduation of $90^{\circ}$, with setting point pairs $1-3$ and $2-4$, and mark a stationary part of the base or a floor to determine the moment of the accurate wheel (roller) shut down against points, marked on the wheel $\mathrm{i}=1 \ldots 4$ (Figure 2).

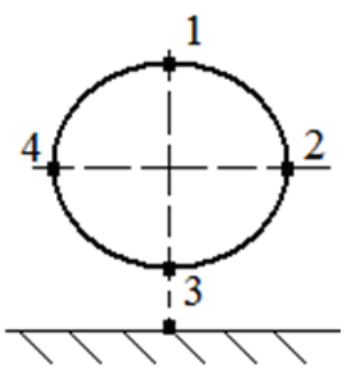

Figure 2. Scheme of point pairs 1-3, 2-4 arrangement for readings and the point of the wheel (roller) shutdown

At setting the roller into position $1-3$, Device 1 (table 1) is mounted on the necks on front lower feeding roller and adjusted on level horizontality by an adjusting screw. Indicator $h$, for Device 1 is shown in Table 1and the data for $h_{11}, h_{13}, h_{31}$, $\mathrm{h}_{33}, \mathrm{~h}_{22}, \mathrm{~h}_{24}, \mathrm{~h}_{42}, \mathrm{~h}_{44}$ are represented in Table 2 and 3. They include deviation from horizontal axis $A_{\Gamma}$ inaccuracies of linker formation AM and inaccuracies, connected with radial beat of necks $A R$ :
$\mathrm{h}_{11}=\mathrm{A}_{\Gamma}+\mathrm{A}_{\mathrm{M}}+\mathrm{A}_{\mathrm{R}}$

In order to exclude inaccuracies of production, Am device is flipped through $180^{\circ}$ (or replace onto another neck) and repeat the measurements. At the same time, roller axis deviations do not change, while inaccuracy of the linker changes its sign.

$h_{13}=A_{\Gamma}-A_{M}+A_{R}$

When $\mathrm{h} 11$ and $\mathrm{h}$ 13, sum up, AM excludes $h_{11}+h_{13}=2\left(A_{\Gamma}+A_{R}\right)$ where $A_{\Gamma}+A_{R}=\left(h_{11}+h_{13}\right) / 2$

For error exception from radial beat AR the roller is flipped through $180^{\circ}$ and the device is mounted into position $3-1$, so the measurement $A 31$ is conducted:

$\mathrm{h}_{31}=\mathrm{A}_{\Gamma}+\mathrm{A}_{\mathrm{M}}-\mathrm{A}_{\mathrm{R}}$

After the device has been flipped through $180^{\circ}$, the measurements are repeated. At this, deviations of roller axis $A_{\ulcorner}$and $A_{R}$ do not change, while the deviation of the device changes its sign.

$\mathrm{h}_{13}=\mathrm{A}_{\Gamma}-\mathrm{A}_{\mathrm{M}}-\mathrm{A}_{\mathrm{R}}$;

$\Sigma \mathrm{h}_{11}+\mathrm{h}_{13}=2\left(\mathrm{~A}_{\Gamma}-\mathrm{A}_{\mathrm{R}}\right) \rightarrow \mathrm{A}_{\Gamma}-\mathrm{A}_{\mathrm{R}}=\left(\mathrm{h}_{31}+\mathrm{h}_{33}\right) / 2$ 
Summarizing (3) and (6), radial beat excludes $\left(A_{\Gamma}+A_{R}\right)+\left(A_{\Gamma}-A_{R}\right)=2 A_{\ulcorner}-A_{R}+A_{R}=2 A_{\Gamma} \rightarrow 2 A_{\Gamma}$ $=\left(\mathrm{h} 1_{1}+\mathrm{h}_{13}+\mathrm{h}_{31}+\mathrm{h}_{33}\right) / 2 \rightarrow \mathrm{A}_{\Gamma}=\left(\mathrm{h}_{11}+\mathrm{h}_{13}+\mathrm{h}_{31}+\right.$ $\left.\mathrm{h}_{33}\right) / 4$

After that the whole series of measurements is repeated in the plane $2-4$. For this purpose, roller is flipped through $90^{\circ}$. The results of the given research are based on the estimation of log-processing equipment condition at the OAO "Woodworking manufacturing plant", YoshkarOla, Russia. They are represented in Table 2.

Table 2: Horizontal axes inclination of lower feeding rollers measurement results

\begin{tabular}{|c|c|c|c|c|c|c|c|c|}
\hline \multirow{2}{*}{$\begin{array}{l}\text { Measurement } \\
\text { Read-ings }\end{array}$} & \multicolumn{8}{|c|}{$\begin{array}{l}\text { Plane } \\
\end{array}$} \\
\hline & \multicolumn{4}{|c|}{$1-3$} & \multicolumn{4}{|c|}{$2-4$} \\
\hline \multicolumn{9}{|c|}{ Front / Rear lower feeding roller/ } \\
\hline & & & \multicolumn{3}{|c|}{$\overline{\mathrm{h}}$} & \multicolumn{3}{|c|}{$\overline{\mathrm{h}}$} \\
\hline & $\mathrm{h}_{11}$ & $\mathrm{~h}_{13}$ & $\mathrm{~h}_{31}$ & $\mathrm{~h}_{33}$ & $\mathrm{~h}_{22}$ & $\mathrm{~h}_{24}$ & $\mathrm{~h}_{42}$ & $\mathrm{~h}_{44}$ \\
\hline Average & $\begin{array}{l}11.383 \\
/ 11.367\end{array}$ & \begin{tabular}{|l}
10.783 \\
$/ 10.933$
\end{tabular} & $\begin{array}{l}10.833 \\
/ 11.213\end{array}$ & $\begin{array}{l}10.883 \\
/ 11.117\end{array}$ & $\begin{array}{c}11.65 \\
/ 11.533\end{array}$ & $\begin{array}{l}11.213 \\
/ 11.183\end{array}$ & $\begin{array}{l}11.567 \\
/ 11.383\end{array}$ & $\begin{array}{l}10.967 \\
/ 11.117\end{array}$ \\
\hline \multicolumn{9}{|l|}{$\overline{\mathrm{h}}$} \\
\hline \multirow{2}{*}{$\begin{array}{l}\text { Deviation from } \\
\text { horisontal-ity }\end{array}$} & \multicolumn{2}{|c|}{$0.6 / 0.434$} & \multicolumn{2}{|c|}{$0,05 / 0,096$} & \multicolumn{2}{|c|}{$0.437 / 0.35$} & \multicolumn{2}{|c|}{$0.6 / 0.266$} \\
\hline & \multicolumn{4}{|c|}{$\begin{array}{c}A_{\Gamma 1-3}=\left(h_{11}+h_{13}+h_{31}+h_{33}\right) / 4 \\
0.3 / 0.265\end{array}$} & \multicolumn{4}{|c|}{$\begin{array}{c}A_{\ulcorner 2-4}=\left(h_{22}+h_{24}+h_{42}+h_{44}\right) / 4 \\
0.52 / 0.308\end{array}$} \\
\hline
\end{tabular}

The suggested device enables to set rollers arrangement with a sufficient accuracy as well as the existing deviation from their horizontality (parallelism), which equals $\left(\mathrm{A}\left\ulcorner\bar{r}=\left|\Delta_{\ulcorner п в} \Delta_{\ulcorner з B}\right|\right.\right.$ $=0.41-0.276=0.144$, scaled to standard length equals $2 \mathrm{~mm}$, that 5 times exceeds the standard rate. Mutual parallel misalignment of feeding rollers in horizontal and vertical planes may serve as one of the reasons for industrial timber production with crooking and flexion.

Application of the new way of measurement based on the technique, mentioned above can also help to evaluate deviations of rollers' axes in a horizontal plane with the help of Device 2, represented in the Table 3 . The measurement results are given in Table 4.

Table 3: Arrangement of lower feeding rollers axes in one horizontal plane

\begin{tabular}{||c|c|c||}
\hline GOST 10294-90 Verification Scheme & Proposed Verification Scheme \\
\hline \hline Tolerance 0,4 for length $1000 \mathrm{~mm} ;$
\end{tabular}


Table 4: Measurement results of inclinations of lower feeding rollers axes arrangement in one horizontal plane

\begin{tabular}{|c|c|c|c|c|c|c|c|c|}
\hline \multirow{3}{*}{$\begin{array}{l}\text { Average } \\
\text { value }\end{array}$} & \multicolumn{6}{|c|}{ Deviation from horizontality, $\mathrm{mm}$} & \multirow{3}{*}{$\begin{array}{c}\text { Average devia- } \\
\text { tion } \\
\text { value } \\
\left(\mathrm{h}_{1-3}+\mathrm{h}_{2-4}\right) / 2\end{array}$} & \multirow{3}{*}{$\begin{array}{l}\text { Deviation from } \\
\text { parallelism on } \\
\text { vertical plane } \\
\left|\mathrm{h}_{1-3}-\mathrm{h}_{2-4}\right|\end{array}$} \\
\hline & \multicolumn{3}{|c|}{ Plane 1-3 } & \multicolumn{3}{|c|}{ Plane 2-4 } & & \\
\hline & $h_{1}$ & $\mathrm{~h}_{3}$ & $h_{1-3}$ & $h_{2}$ & $\mathrm{~h}_{4}$ & $h_{2-4}$ & & \\
\hline $\begin{array}{l}\text { Right } \\
\text { side }\end{array}$ & 11.45 & 11.05 & 11.275 & 11.6 & 11.5 & 11.55 & 11.41 & 0.275 \\
\hline Left side & 10.85 & 111.05 & 10.95 & 111.1 & 11.0 & 11.05 & 11.0 & 0.1 \\
\hline \multicolumn{3}{|c|}{$\begin{array}{l}\text { Deviation from horizontality } \\
\qquad\left(A\ulcorner=) h_{\Pi}-h_{ת}\right.\end{array}$} & 0.325 & & & 0.5 & 0.41 & 0.187 \\
\hline
\end{tabular}

It was found that actual deviation from horizontality equals $0.41 \pm 0.09$ on the roller length of $700 \mathrm{~mm}$, modified to standard condition of 1000 $\mathrm{mm}$ accounts for $0.51 . \mathrm{mm}$, which is just above the standard value of $0.4 \mathrm{~mm}$.

\section{CONCLUSION}

1) Methods, proposed in the given research, along with calculation examples permit to achieve (by means of immediate control) consistent results of accuracy of mutual arrangement of feeding mechanism parts and to determine availability of deviations from parallelism in a vertical plane and, above all, respective horizontality.

2) Thanks to simplicity of construction these devices could be produced on any woodworking plant, providing $0.05 \mathrm{~mm}$ accuracy.

3) The main advantage of the recommended devices is the opportunity to evaluate woodworking equipment rollers arrangement in a horizontal plane even if a considerable deviation exists and far exceeds the limits of machinist level measurements, which is applied for estimation of equipment conditions.

\section{REFERENCES}

1) Eklund, (2000), U Influencing factors in sawing accuraly in a bandsawill, Holz Roh - und Werkst.

2) GOST 2140-81 visible defects, of wood. Classification, terms and definitions, methods of measurement (1981), Moscow, 118p.

3) GOST 5524 - 75 Saws for vertical gang mills, (1975), Moscow, 10p.

4) GOST 10294 - 90. Woodworking equipment,
Vertical two-storey saw frames. Basic parameters. Standards of accuracy (1990), 9p.

5) GOST 20911 - 89. Technical diagnostics. Terms and definitions, (1989), Moscow, 9p.

6) GOST 25338 - 82. Woodworking equipment. Accuracy and rigidity test. General requirements, (1991), Moscow, 7p.

7) Tarasova O. G. Issledovanie i sovershenstvovanie standartnyh sposobov kontrolja i povyshenija kachestva piloprodukcii: dis.... kand. tehn, nauk. - M. 2011. - 259 p.

8) Pat. 2538480 Rossijskaja Federacija MPK V27B 27/00 G01C 9/24 Sposob dlja ocenki gorizontal'nosti ploskih i cilindricheskih poverhnostej / Bojarskij M.V., Tarasova O.G. №2012153655/13; Bojarskij M.JuV., zajavl. 11.12.2012; 10.01.2015 Bjul. № 1 .

9) RPI 6.1-00, Rukovodjashhie tehnicheskie materialy po opredeleniju rezhimov pilenija na lesopil'nyh ramah (1987), Arhangel'sk: CNIIMOD.

10) Tarasova, O.G., S.V. Shlychkov, (2016), Vlijanie defektov tehnicheskoj sistemy na parametry proizvodimyh pilomaterialov, Remont, vosstanovlenie, modernizacija. № 1, p. 13-17.

11) Tehnologicheskie rezhimy RPI 6.1-00. Podgotovka ramnyh pil (1982), Arhangel'sk, CNIIMOD.

12) Vuorilehto, Jaakko. (2002) Quelity yield capability of a breakdown sawing process, Jaakko Vuorilehto, Forest Prod. J, 52№4, P. 77-81.

Paper sent to revision: 17.11.2016.

Paper ready for publication: 25.04.2017. 